\title{
Improvement of system of touristic-recreational complex management at regional level
}

\author{
Galimova Leysan Ismagilovna \\ Kazan Federal University \\ Kazan, Russia
}

\author{
Galimov Shamil' Shagitovich \\ Kazan Federal University \\ Kazan, Russia
}

\author{
Gainetdinov Vladlen Il'gizovich \\ Kazan Federal University \\ Kazan, Russia
}

\begin{abstract}
Ensuring the stable development of socio-economic subsystems of the national economic system in the conditions of stagnation involves the formation of mechanisms for effective management of industries and complexes primarily at the regional level, because the implementation of management actions at the regional level can take into account not only the specifics of activities in industries and fields of activity, but also territorial features. The current state of the system of management of the national economics of the Russian Federation and its meso-level subsystems is such that the activities of individual subsystems of regional management are in conflict with the control actions of others, and, as a result, the achievement of the goals is impossible, because it's connected with the necessary use of limited resources. In the article we discuss the effective functional system of regional management of the touristic-recreational complex, as well as a model that will ensure the formation of a management system based on the application of market principles. The article presents a flexible adaptive management system of the touristic complex of the region by the example of the Republic of Tatarstan, in which the control actions are implemented in accordance with market trends.
\end{abstract}

Keywords- region; tourism; regional management; touristrecreation complex; Russian Federation; the Republic of Tatarstan; UNESCO;

\section{INTRODUCTION}

The national economic system in relation to the development of its region and increasing the attractiveness of non-primary industries is focused on reducing the imbalance of the social-economic system. In the vast majority in the regions of the Russian Federation, the branches of specialization are raw materials industries, in which raw materials enterprises are the centers of attraction of such resources as labor, financial, technical and technological and information. So, the basis for changing the structure of the national economy should be mechanisms to increase the attractiveness of other sectors in terms of resource flows. The main non-resource sector in the modern global economic system is the touristic-recreational industry, which accounts for up to $15 \%$ of the world trade in services.
In the Russian Federation, an effective system of public administration at the macrolevel is complicated by the sale of areas and territorial distortions, both in the environmental and in social-economic terms. The presence of these factors determines the feasibility of delegating significant powers to the regions in which these disparities are generally less significant.

Management of the touristic-recreational complex is preferably implemented primarily at the regional level (mesolevel), which does not contradict the existing programs of the strategic document regulating the development of the touristicrecreational industry in the Russian Federation. It will help in solving problems taking into account regional features.

Today, it is necessary to define approaches to the development of the touristic-recreational complex management system in the region, which will make it possible to achieve effective interaction of the state, business structures and households in the priorities of the Russian economy in the non-resource sectors, such as tourism, which is one of the most profitable types of business in the world after the export of oil and cars.

According to the forecast of the World Touristic Organization (UNWTO), by 2030 the number of international tourists travel will increase from 1234 million per year to 1.8 billion, that is almost more than 1.5 times and therefore profit from tourism will increase up to 2 trillion dollars per year. The proportion of the domestic tourism is about $80 \%$ of the total number of tourists in the world and the proportion of domestic and international trips in the world until 2030 become 10:1 [9].

The study is based on the theory of system and economic analysis, general scientific methods of cognition by induction and deduction, collective and qualitative analysis.

The tourism management system includes the subject and object of management. The ambiguity and diversity of the concept of tourism management object determines the complexity of its management. The theory of control in its classical form offers a fairly clear definition of the control 
object - "something at which cognitive or other activities are aimed" [2].

In our case, the object of management is a touristicrecreational complex, consisting of two subsystems - "region" and "tourism". Trust and inconsistency in the object under study are due to the cut and ambiguity of the phenomena and processes occurring with them.

The word "region" has more than 100 definitions. The official definition of this word contains at the main provisions of the regional policy in the Russian Federation, approved by the decree of the President of the Russian Federation as of June 21, 2004, and according to this document, we determine a region as a part of the territory of the Russian Federation, which has common nature, socio-economic, national-cultures and other conditions [8].

\section{RESULTS}

A well-known specialist in the field of regional economics, N. N. Nekrasov, considers the region as "crap territory of the country with more or less or prod conditions, and, mainly, the nature of the direction of development give forces on the basis of a set of complex of natural resources with the corresponding current and prospects of social infrastructure".

In the definition of V. I. Butov and V. G Ignetov, one emphasizes the importance of the factor of regional development manageability: "the region is a social-economical space that characterizes the structure of production of all forms of ownership, the concentration of population, jobs, the relationship of human life based on piece of space and time, having local government of its territory (region, region, republic)" [3].

Specialists in the field of regional science and heads of regions of the Russian Federation under the regions understand the subject of the Russian Federation and highlight the following features of the regions:

\section{1. unity and integrity of the region;}

2. manageability in the form of political and administrative authorities;

3. the complexity of the economy, expressed in the commonality and unity of the economy;

4. specialization and entry to the market of demanded products;

5. availability of personal in the production and nonproduction sectors corresponding to the level of education and qualification.

At the heart of the formation of the economic category "touristic-recreational complex", we can talk only about the specialization of tourist activities of the national or regional economy.

We agree with the opinion of the researchers, who consider the category of "tourism" as a tourist-recreation complex.
Researchers give various distinct of the touristicrecreational complex. Kotlyarov E. A. in his work introduces the concept of "territorial-recreation complex": the territorialrecreation complex is part of the overall economic complex of the territory of different levels and is a combination of leisure facilities and related infrastructure enterprises, obedient to these production and economic ties, also, the joint use of the geographical position, natural and economic resources of the territory occupied by the complex [7].

We take the definition of Koblova A. A.: "The touristicrecreational complex is a part of the general economic complex of the region (territory), which is a combination of tourists, leisure and related businesses and organizations whose activities are coordinates of the state and (or) other structure and is proven to create, promote and implement our product uniquely, taking into account the optimal use of tourist-recreation potential of the territory" [6].

The touristic-recreational complex has natural and socialeconomical conditions of formation. Formation of the touristic-recreational complex most often lies in the proposal that determine touristic-recreational specialization of the complex. For example, he presence of curative mud in Bakirovo leads to the creation of the balneological resorts in the Republic of Tatarstan, tear a combination of comfortable gentle slopes in the Verkhniy Uslon area of the Republic contributes the organization of the ski centers.

Based on the experience of the Republic of Tatarstan, it is possible to propose two ways of forming the touristicrecreational complexes. At the heart of the first path there is the restoration, reconstruction and development of existing recreation facilities-tourists which were formed and have a functioning tourist-recreation farm (Kazan agglomeration, Zelenodolsk, Spassk, Elabuga districts).

The second way involves the new development of areas where touristic-recreational facilities are not simple in purpose. Touristic-recreational complexes may arise:

- on local natural resources of the region, which will act as the main stimulator of the development of tourist and recreational complex (Blue lake, mount Chatyr Tau with a colony of marmots);

- on the basis of large urban agglomerations with a developed economy (Kazan, Nizhnekamsk), where residents of large cities form the demand for recreation, and this affects the organization of recreation. As a rule, these are areas with favorable economical and geographical location, developed transport network and production facilities capable of serving tourist and recreational facilities;

- based on the influence of social, national, historical, architectural, archaeological and other factors (Bulgar, Bilyarsk and Sviyazhsk).

Effective management of the touristic-recreational complex as a territorial system involves the search, introduction and adaptation to the specific economic conditions of the economic system of the region, innovative tools and methods to improve decision-making processes. Taking into account the increased complexity and structural 
diversity of elements and subsystems of the touristicrecreational complex as an object of regional management in the existing conditions of uncertainty and instability of the internal and external environment, there is a need to use the reserves inherent in the modernization of the management of the tourist and recreational complex.

The main aim of the regional touristic-recreational complex is defined as the formation of a competitive touristicrecreational industry as one of the leading branches of the territorial specialization of the region, which will further ensure the growing demand of consumers to meet their needs for tourist and recreational services. Effective functioning will have a positive impact on the socio-economic development of the region by increasing the revenues of the national and municipal budgets, the inflow of investments, increasing the number of jobs, improving public health, preservation and rational use of cultural, historical and natural heritage. The main role is played by the system of management of services of the touristic-recreational complex. Application of modern methods of cultural communication allows coordinating effectively the dynamic situations peculiar to the sphere of recreational services. A well-functioning management system provides the basis for the most effective integration of individual service operations. Using the principles of planned budgeting, it is necessary to build an effective scheme of redistribution of financial flows from ultra-profitable sectors (entertainment industry, etc.) to less profitable (for example, accommodation) in the interests of sustainable economical development of the whole complex. We should not forget that the touristic-recreational complex provides the needs for appropriate services not only for tourists, but also for the local population, thereby contributing to a significant improvement in the quality of life in the region.

It is necessary to build a hierarchy of management of enterprises and organizations of the touristic-recreational complex to consider the possibility of coordination and integration of service processes of related enterprises, to expand the production capacity of tourist and recreational production, to increase productivity and improve its quality. This is ensured by the interconnection of production, investment and innovation potential of enterprises included in the complex, in the implementation of which the achievement of the main goal is the best performance of services.

\section{CONCLUSION}

The improvement of the macroeconomic situation will play a decisive role in the transition to the trajectory of sustainable development of the region with recreational specialization. Economic measures such as removing obstacles to the development of small, medium and large businesses; participation of public authorities in the division and reduction of the level of economic risk in the creation of new tourist and recreational services will be required to improve the sustainability of regional development; weakening or abolishing administrative and fiscal measures that impede the introduction of new methods of regional development management.

\section{References}

[1] L.I. Abinova, Some features of development of the tourist-recreational complex of the region, Today and tomorrow of the Russian economy, 2010, № 33, pp. 164-166.

[2] L.I. Abinova ,The development of the management system of the tourist and recreational complex of the region (on the example of the Republic of Tatarstan). Abstract of dissertation for the degree of candidate of economic sciences, Acad. Exercise, "TISBI", Kazan, 2010

[3] V.I. Butov, V.G. Ignatov, N.P. Ketova, Fundamentals of regional economics: study guide. Moscow, Rostov on Don, 2000.75, K. Elissa.

[4] K.N. Yusupov, Reproductive aspects in the national economy (regional aspect), scientific. ed., Ufa: RIO BashGU, 2004.

[5] G.V. Gutman, A.A. Miroedov, S.V. Fedin, Regional Economy Management, Moscow, 2001, M. Young, The Technical Writer's Handbook, Mill Valley, CA: University Science, 1989.

[6] A.A. Koblova, Recreational and tourist complex as an object of regional management. Collection of scientific works of the North Caucasus State Technical University. Economy Series, 2005, No. 2, pp. 29.

[7] E. A. Kotlyarov, Geography of recreation and tourism, the formation and development of territorial and recreational complexes, Moscow, Thought, 1978.

[8] Presidential Decree No. 791 of June 21, 2004 (as amended on January 12, 2010) "On Approval of the Regulations on the Office of the President of the Russian Federation on Domestic Policy", "Meeting the Legislation of the Russian Federation", June 11, 2004, No. 24, Art. 2415 .

[9] B.M. Eidelman, O.A. Bunakov, S.S. Galimov, L.I. Galimova, M.V Rozhko City branding in Russia: Main trends, problems and development prospects, Social Sciences and Interdisciplinary Behavior: The 4th International Congress on Interdisciplinary Behavior and Social Science (ICIBSoS 2015), Kazan Federal University, Kazan, Russia, 2223 October 2015 \& Arya Duta hotel, Jakarta, Indonesia, 07-08 November 2015, pp. 149-151.

[10] UNWTO Tourism Highlights, 2017 Edition. UNWTO http://tourlib.net/wto/WTO_highlights_2017.pdf 